Pediatr Clin North Am. 2014 October ; 61(5): 873-888. doi:10.1016/j.pcl.2014.06.002.

\title{
Prevention of Child Maltreatment
}

\author{
Wendy Gwirtzman Lane, MD, MPH [Assistant Professor] \\ Department of Epidemiology and Public Health, Department of Pediatrics, University of Maryland \\ School of Medicine, 660 West Redwood Street, Baltimore, MD 21201, (410) 706-7865, \\ wlane@epi.umaryland.edu
}

\section{Abstract}

Pediatricians and other health care providers can play a number of important roles in the prevention of child maltreatment. As part of routine patient care, pediatricians can provide anticipatory guidance for effective discipline and parent-child communication, screen for maltreatment risk factors, and refer parents and families to effective community-based programs. This article will help pediatricians incorporate child abuse prevention into their practice. Resources for systematizing anticipatory guidance and child maltreatment risk factor screening will be described. The modalities and strengths and weaknesses of community-based prevention programs will be discussed, and providers will be given tools to identify the effectiveness of available community-based programs. At a broader level, the article will describe ways that pediatricians can advocate at the local, state, and national level for policies and programs that support families and children.

\section{Keywords}

Child abuse; child neglect; prevention; health promotion; primary care

\begin{abstract}
Child abuse prevention needs to be explained and understood within a broad context of child wellbeing. A child's experiences do not occur in a vacuum, but rather they occur within the context of family, community, and society. Risk factors for maltreatment such as parental depression, substance abuse, or lack of social support may lead to other adverse outcomes in addition to maltreatment. Likewise, interventions to prevent maltreatment may have other positive effects on children and families, including improved development, improved maternal health, enhanced parent child communication, decreased use of public assistance and decreased involvement in the criminal justice system. ${ }^{1-5}$ For these reasons, many organizations and experts, including the American Academy of Pediatrics (AAP), The Centers for Disease Control and Prevention (CDC), and the Harvard Center on the Developing Child directly link child maltreatment prevention to strengthening families,
\end{abstract}

\footnotetext{
(C) 2014 Elsevier Inc. All rights reserved.
}

Publisher's Disclaimer: This is a PDF file of an unedited manuscript that has been accepted for publication. As a service to our customers we are providing this early version of the manuscript. The manuscript will undergo copyediting, typesetting, and review of the resulting proof before it is published in its final citable form. Please note that during the production process errors may be discovered which could affect the content, and all legal disclaimers that apply to the journal pertain. 
improving developmental outcomes, and promotion of child and family safety, stability, and nurturance. $^{6-8}$

\section{The Role of Pediatric Health Care Providers in Child Maltreatment Prevention}

Pediatricians and other health care providers can play a number of important roles in the prevention of child maltreatment. As part of routine patient care, pediatricians can provide anticipatory guidance, screen for maltreatment risk factors, and refer parents and families to effective community-based programs. These efforts can be integrated into routine care without increasing visit length if parents complete screening questionnaires before the visit and listings of community resources are readily available. At a broader level, pediatricians can advocate at the local, state, and national level for policies and programs that support families and children. Each of these roles will be discussed in this chapter. A summary is provided in Box 1.

\section{Screening for Maltreatment Risk Factors and Identification of Families at Risk}

From an ecological perspective, interactions among and between child, parent, family, and community/society may all increase the likelihood of maltreatment. ${ }^{9,10}$ Any characteristic that makes a child difficult to care for, including physical, emotional, behavioral, or developmental disabilities may increase risk. ${ }^{11-13}$ Parents with mental health problems, limited social support, limited knowledge of normal child development, low sense of parenting competence, or harsh, inattentive, or inconsistent parenting may be at higher risk of abusing or neglecting their children. ${ }^{14-20}$ Families experiencing intimate partner violence or who have non-biologically related adults in the home may also be at increased risk. ${ }^{21,22}$ Finally, a number of community and societal factors such as violent neighborhoods, and inadequate social welfare programs like food and housing assistance may increase stress on families and increase the likelihood of maltreatment. ${ }^{23,24}$ Table 1 summarizes major maltreatment risk factors.

A number of protective factors should also be noted. Social support is an important protective factor; families with higher levels of social support have lower rates of physical abuse and greater use of discipline strategies other than corporal punishment. ${ }^{25,26}$ Selfefficacy, an individual's belief in his or her ability to succeed, is another characteristic that can limit the adverse effects of risk factors. Some parents are very adept at identifying and securing helpful resources and services such as home nursing for a sick child, or a child care center that serves children with developmental disabilities. A parent's sense of competence in child rearing may enable her to better cope with the challenges of raising children. ${ }^{27}$ Children with high intelligence, self-esteem, and/or self-efficacy, are involved with extracurricular activities or religious institutions, or who have a supportive adult involved in their lives may be less likely to suffer negative sequelae from maltreatment. ${ }^{28}$

A child health professional who is familiar with child maltreatment risk factors can work with families to identify and address these risks. Because many high risk parents have 
limited health care access and do not seek out supportive services, they may have more contact with their child's primary care provider than any other professional. Child health professionals are therefore uniquely suited to identify and address child maltreatment risk.

As with any screening program, screening for child maltreatment risk factors should be focused on problems for which effective treatment is available, such as parental depression and substance abuse. Universal screening (i.e. screening all families in a primary care practice) is recommended because it eliminates the stigma of screening selected families, and reduces the likelihood of missing at-risk families. A number of questionnaires that screen for child maltreatment risk factors have been developed and validated. ${ }^{29-37}$ Although brief, most identify only a single risk factor. ${ }^{36}$

Several screening tools identify multiple maltreatment risk factors. The SPARK (Structured Problem Analysis of Raising Kids) questionnaire identifies factors that may increase child maltreatment risk such as child health, development and behavior, parenting approach, social contacts and informal support, and family and community environment. ${ }^{38,39}$ The 3 step model starts with detection of problems and concerns. This is followed by an assessment of the extent and impact of problems and the parents' perception of need for support. The final step involves making decisions about next steps. The questions are intended to be administered as part of a structured interview, which takes, on average, 29 minutes to complete. Providers are taught how to administer the SPARK in a half-day training session. A recent study has shown that the included risk factors were strongly predictive of child protective service reports. ${ }^{39}$ However, no data has been published on the effects of SPARK in reducing child maltreatment.

Another model that incorporates a multi-risk factor screening questionnaire is SEEK - A Safe Environment for Every Kid. The Parent Screening Questionnaire (PSQ), a component of SEEK, is a single-page document that asks about multiple maltreatment risk factors, including parental depression, substance abuse, social support, intimate partner violence (IPV), major parental stress and food insecurity. ${ }^{36}$ In order to reduce the stigma associated with asking sensitive questions, an introductory paragraph adopts an empathetic tone and notes that parenting can be challenging for anyone. It also notes that the survey is given to all parents bringing their children for a check-up.

The SEEK model includes several other components in addition to the PSQ. Because many pediatricians may not have had training in addressing complicated issues such as IPV and parental substance abuse, training and skill building are incorporated. Motivational interviewing techniques are introduced as a means of enhancing parents' readiness to change. These techniques have proven effective for many types of behavior change, and pediatricians can become skilled with training and practice. With support from the Doris Duke Foundation, these training modules are now available on-line at: https:// theinstitute.umaryland.edu/SEEK/. The SEEK website also includes algorithms for further assessment and parent handouts that address each risk factor. The SEEK model ideally includes a clinical social worker or mental health professional to assist with family assessments and referrals, either in person or by phone. Alternatively, pediatricians who 
have been trained to briefly assess and initially address identified problems may implement the SEEK model with the help of office staff to facilitate referrals.

The effectiveness of SEEK has been studied extensively. Two studies have demonstrated the SEEK model's effectiveness in reducing child maltreatment. ${ }^{40,41}$ One study was conducted in a pediatric resident continuity clinic based in an urban, inner city community. The other was conducted at 18 mostly suburban, private primary care practices. SEEK has been endorsed as a promising practice by the federal Agency for Healthcare Research and Quality (AHRQ) Health Care Innovations Exchange, and some materials are included in Bright Futures guidelines for anticipatory guidance. An economic analysis of SEEK demonstrated that the program would save money by reducing the need for medical and mental health expenses. ${ }^{42}$ Of particular importance to the busy pediatrician, practices that implemented the SEEK model did not increase the average time spent with patients.

\section{Prevention Programs Rooted in Models of Anticipatory Guidance}

A number of programs use anticipatory guidance to help parents effectively manage situations that might increase the risk of maltreatment. Two programs have specifically focused on the stress associated with infant crying and preventing abusive head trauma (shaken baby syndrome). Dias et al developed a hospital-based postpartum intervention that taught parents the dangers of shaking babies. ${ }^{43}$ Equally important, it taught parents how to manage the stress that they might feel when their infant cries inconsolably. After receiving the educational materials, parents were asked to sign a commitment statement stating that they would not shake their baby and they would teach other caregivers not to shake. An ecologic study comparing change in rates of abusive head trauma in the Buffalo, NY area where the intervention was implemented with rate changes in neighboring Pennsylvania during the same time period showed a $47 \%$ decrease in the rate of abusive head trauma in the intervention community, but no change in rates in the control communities. Unfortunately, a case-control study of a similar intervention implemented in Utah did not show significant reductions in abusive head trauma. ${ }^{44}$

The Period of Purple Crying program is also focused on the parenting response to infant crying. A video and brochure provide information about infant crying behavior with advice on how to reduce infant crying and address the associated parenting stress. Two randomized trials demonstrated significant improvement in knowledge about and response to crying. Because the incidence of abusive head trauma is relatively low (approximately 30 cases per 100,000 infants), enrollment of enough families to detect significant differences in rates of abusive head trauma between the intervention and control groups was not feasible. ${ }^{45,46}$ Therefore, the studies were not designed to examine this outcome. The program has expanded from their original sites in Vancouver, BC and Seattle, WA to many other communities in the U.S. and Canada. A statewide campaign in North Carolina has incorporated in-hospital postpartum education, community-based education in primary care offices and health departments, and a media campaign. ${ }^{47}$ To date, there have been no publications specifically examining whether the intervention leads to a reduction in the rate of abusive head trauma. 
The American Academy of Pediatrics has developed two programs for primary prevention of child maltreatment in the clinical setting. Connected Kids: Safe, Strong, Secure is a resiliency-based educational program for parents and providers focused on managing challenging developmental stages, providing effective discipline, and other topics. ${ }^{48}$ While the developers have demonstrated that implementation is feasible, there has not been any evaluation of program effectiveness in reducing maltreatment rates or other benefits. Practicing Safety is another AAP-developed program that helps providers screen for and address maternal depression, and uses anticipatory guidance to help parents cope with challenging developmental stages such as infant crying and colic and toilet training. ${ }^{49}$ It was initially implemented as a Quality Improvement Innovation Network (QuIIN) project to increase attention to and address specific risk factors for child maltreatment. Participants demonstrated changes in practice behavior, but effects on child maltreatment were not examined.

\section{Community-Based Prevention Programs}

In addition to providing anticipatory guidance and screening for maltreatment risk factors, pediatricians can also refer families to community-based programs, and encourage them to participate. In order to do so, however, pediatricians must be aware of what programs are available in their communities. Gathering this information may initially require several hours of pediatrician or office staff time, followed by periodic updates. Community resource information may be available from one's local or state health department, United Way agency, and/or through an internet search, supplemented by phone calls and requests for brochures and program information. Identifying and communicating periodically with key contact persons at community-based agencies may also be worthwhile. Brief conversations can be helpful in learning more about the program, and in collaboratively addressing the needs of referred families. In addition, families in need of services may be more willing to engage when their pediatrician is familiar with program staff and services.

Pediatricians also must be knowledgeable about the quality and effectiveness of the available programs, keeping in mind that many programs have had little or no formal evaluation. A number of websites focused on evidence-based interventions can help pediatricians acquire this knowledge by summarizing key information. Most provide program descriptions as well as information on program location(s), targeted populations, research outcomes, and effectiveness ratings. Table 2 lists several useful sites.

There is a great deal of variability among programs. While some explicitly focus on child abuse prevention, the goals of others are framed in a broader context, such as enhancing parenting skills. The background and training of program staff varies considerably. Professionals such as nurses or social workers work directly with participants in some programs. These professionals may be equipped with a large fund of knowledge and years of experience. However, some programs prefer using lay persons from the intervention community because of the potential for better connections with participants. Some programs have been studied extensively with rigorous methods including randomized controlled trials, and both process and outcome evaluations; others have not been as carefully or extensively evaluated, and many have not been evaluated at all. 
When successful programs are replicated, fidelity to the original model becomes an important consideration. Consistency in training, implementation, and oversight may help ensure that all program components are implemented properly. However, sometimes program changes are needed with replication, particularly when they are implemented in communities that are culturally or geographically different than the original intervention community.

Keeping families engaged in community-based services can be challenging. Many families referred to community-based programs struggle with stressors such as poverty, singleparenthood, intimate partner violence, and depression, in addition to pregnancy and parenthood. High quality interventions may better engage and retain participants than lower quality programs. ${ }^{50}$ Engagement and retention is often more difficult in families coping with intimate partner psychological aggression, substance abuse, and depression. ${ }^{50}$ If pediatricians screen, identify, and help families access services for these problems, they may reduce child maltreatment by both ameliorating risk factors and improving communitybased program participation.

Most community-based programs fall into one of two categories: home visiting and parent training. However, some parent training programs include a home visiting component, and many home visiting programs include parenting skills training. A review of twelve carefully evaluated community-based programs (including both home visiting and parent training) with control groups and measurement of child abuse outcomes demonstrated an overall positive effect of the interventions. The weighted average rate of child maltreatment was $2.9 \%$ lower in intervention families compared to controls. ${ }^{51}$ However, only four of the twelve programs showed a statistically significant reduction in substantiated maltreatment rates. The most effective programs had a high dosage of intervention and comprehensive services addressing multiple family needs. Highly trained service providers also increased program effectiveness.

Home visiting programs assign a professional or layperson to serve families in their own environment. Services may include an assessment of needs, case management, education, emotional support, and role modeling. Home visitors assist families in accessing needed services such as health insurance, WIC, mental health and substance abuse treatment, housing assistance. Most begin during pregnancy or shortly after birth.

The 2010 federal Patient Protection and Affordable Care Act included funding for evidencebased home visiting through the Maternal, Infant and Early Childhood Home Visiting Program (MIECHV). At least $75 \%$ of MIECHV community funding must be spent on evidence-based home visiting programs. In order to determine which programs would be designated as "evidence-based", the U.S. Department of Health and Human Services (DHHS) conducted a systematic review, the Home Visiting Evidence of Effectiveness (HomVEE). Data from HomVEE led DHHS to designate 12 programs as meeting evidencebased criteria (Box 2) ${ }^{52}$ It is important to note that while all DHHS designated programs have shown positive outcomes for children, not all have demonstrated effectiveness in preventing child abuse and neglect. Descriptions of several widespread HomVEE designated programs with evidence of child abuse prevention are provided in Table $3 .{ }^{53}$ 
With the recent increases in home visiting funding, pediatricians may find that more resources are available for their patients, particularly those living in high-risk communities. However, pediatricians should also be aware of some of the challenges of program expansion and replication. Some interventions that worked well in relatively small randomized controlled trials may be less effective when implemented on a larger scale, with different community and service provider characteristics, and with fewer resources available for oversight and evaluation. Some programs that have demonstrated effectiveness in clinical trials have not performed as well when replicated. ${ }^{54,55}$ Pediatricians can assist families by advocating for adoption of high quality programs, with funding for ongoing evaluation. In addition, pediatricians should develop relationships with local home visitation programs to facilitate coordination of care in addressing family needs.

Parent training programs are intended to improve parents' comfort and competence with parenting. Program components may include child development, responsiveness, sensitivity and nurturing, positive interactions, emotional communication, and disciplinary approaches. The specific services and mode of implementation vary by program and may include individual, group, office-based, and/or home-based programs. Unfortunately, few program evaluations have directly measured child maltreatment outcomes, instead focusing on potential mediators such as child-rearing skills and emotional adjustment. A 2009 review of program reviews identified two meta-analyses (integration of data from multiple studies that examine similar outcomes) showing small to medium effects of parent training programs; others showed effects on child maltreatment risk factors, but not on actual maltreatment. ${ }^{56}$ Several meta-analyses of parent training programs have identified characteristics that may improve program effectiveness. ${ }^{57-60}$ Programs that include multiple modalities and higher dosage of intervention are more likely to be successful.

Multimodal community-based interventions have also been developed, which may include home visiting, parent training, public service announcements, and/or primary care anticipatory guidance. One of the most effective programs is Triple P-Positive Parenting Program. Triple P focuses on addressing children's behavioral, emotional, and developmental problems, enhancing family protective factors, and reducing family risk factors for maltreatment. ${ }^{61}$

Five tiers of Triple P services are available to families; the services received depend on family needs. Tier 1 services are universal, and include print and electronic media messages. Goals are to increase awareness of parenting challenges and reduce or eliminate the stigma associated with participation in parenting programs. Tier 2 services are intended to address discreet behavioral or developmental concerns (e.g. toilet training, sleep). Trained program staff offer assistance by phone or in-person in a few brief sessions (e.g. two 20-minute sessions) or 60-90 minute seminars. More serious problems may require level 3 services; about 4 80-minute sessions that include active skills training. When parents have multiple concerns about their child or the child has more severe behavior problems, tier 4 services may be warranted. Assistance may be provided as individual, group, or self-directed services for up to 12 weeks. Tier 5 services are provided when, in addition to significant child behavior problems, parents have their own issues to address. Additional services may involve home visits and mental health services for parents. 
An evaluation of Triple P implementation in 18 South Carolina counties showed promising effects in reducing child maltreatment. Counties that implemented Triple $\mathrm{P}$ had significantly lower rates of substantiated child maltreatment, fewer out of home placements, and fewer child maltreatment injuries that required inpatient or emergency department care. ${ }^{62}$

\section{Sexual Abuse Prevention}

Prevention of child sexual abuse is addressed separately in this article because it poses unique challenges in developing effective interventions. While many caregiver risk factors have been identified for physical abuse and neglect, caregiver characteristics are much less predictive of sexual abuse. There is no typical profile of a sexual abuse perpetrator. This makes it challenging to develop prevention programs predicated on keeping children away from risky caregivers. In addition, some adults are uncomfortable with any discussion about sexuality as it pertains to their children. They may therefore be reluctant to participate in prevention programs directed at parents, and even more reluctant to allow their children to participate in prevention programs.

Pediatricians may be uniquely suited to educating parents about preventing sexual abuse. Parents typically listen to and trust their provider's recommendations and they have frequent contact with their pediatrician during the first few years of a child's life. While there are no studies examining the effectiveness of anticipatory guidance in reducing victimization, some general concepts can be extrapolated from other interventions. Several key concepts are summarized in Table 4.

Education-based prevention programs became prevalent in the 1980s and have been extensively studied and critiqued. Most are school-based and focused on understanding and protecting personal boundaries, identifying and avoiding dangerous situations, refusing sexual approaches and invitations, and telling an adult if inappropriate behavior occurs. Evaluations of these programs show that children do learn the concepts being taught, and that they respond appropriately when challenged during simulations. ${ }^{63-66}$ They also may lead to increases in sexual abuse disclosure, and decreased likelihood of self-blaming. ${ }^{67,68}$

Few studies examining whether these programs lead to reductions in sexual abuse have been published. One retrospective case-control study with college-student participants did demonstrate a lower rate of sexual abuse among those students who recalled participation in a school-based program. ${ }^{69}$ However, a prospective cohort study of 10-16 year old students did not show any difference in victimization rates between those who did and did not participate in a prevention program. ${ }^{67}$ Critics of child-focused prevention programs have argued that it is unfair to expect children to bear the responsibility for preventing sexual abuse, and that it may be harmful to tell children that someone close to them could abuse them. However, program evaluations have identified few negative consequences. ${ }^{66,70}$

Several public health media campaigns have been developed and disseminated in recent years. STOP IT NOW is a program first introduced in Vermont that incorporated public service announcements on television and radio, newspaper articles, bus advertising and an interactive website. Evaluation demonstrated greater awareness about sexual abuse, and an increased number of helpline calls. ${ }^{71}$ Darkness to Light educates parents and child serving 
organizations about methods to keep children safe, including the avoidance of one adult-one child situations. A media campaign evaluation found that the program led to increased knowledge of sexual abuse, and improvements in protective behavior on hypothetical vignettes. Unfortunately these effects did not persist 9 months post-intervention. ${ }^{72}$ The Enough Abuse campaign takes a multi-pronged approach, incorporating education of adults and children, and advocacy efforts to ensure child-safety focused policies and regulations.

\section{Advocacy}

Pediatricians can be advocates for child maltreatment prevention in multiple ways, at the level of the individual child, parent, community, and society. Helping parents meet their children's needs is advocacy on behalf of individual children who may be unable to communicate these needs. Acknowledging parental stress, identifying other maltreatment risk factors and motivating and facilitating help-seeking efforts is another form of advocacy. Pediatricians can play leadership roles in implementing hospital-based abusive head trauma prevention programs and practice-based policies for risk-factor screening and anticipatory guidance. While pediatricians may not have direct involvement in community-based prevention programs, they can advocate for implementation and dissemination of quality home visitation and parent training programs in their community or state. Finally, pediatricians can advocate for increased resources to help families meet the needs of their children.

\section{References}

1. Andrews SR, Blumenthal JB, Johnson DL, et al. The skills of mothering: a study of the Parent-Child Development Centers, Monographs of the Society for Research in Child Development. 1982; 47:181.

2. Olds DL, Eckenrode J, Henderson CR, et al. Long-term effects of nurse home visitation on maternal life course and child abuse and neglect: Fifteen year follow-up of a randomized controlled trial. JAMA. 1997; 278:637-43. [PubMed: 9272895]

3. Duggan AK, McFarlane EC, Windham AM, et al. Evaluation of Hawaii's Healthy Start Program. The Future of Children. 1999; 9:66-90. [PubMed: 10414011]

4. Kitzman H, Olds D, Henderson R, et al. Effect of prenatal and infancy home visitation by nurses on pregnancy outcomes, childhood injuries, and repeat childbearing: A randomized controlled trial. JAMA. 1997; 278:644-652. [PubMed: 9272896]

5. Olds DL, Henderson CR, Phelps C, et al. Effect of prenatal and infancy home visiting on government spending. Medical Care. 1993; 31:155-174. [PubMed: 8433578]

6. Flaherty EG, Stirling J, Clinical Report. The pediatrician's role in child maltreatment prevention Pediatrics. 2010; 126:833-841.

7. National Center for Injury Prevention and Control. Centers for Disease Control and Prevention. Strategic Direction for Child Maltreatment Prevention: Preventing child maltreatment through the promotion of safe, stable, and nurturing relationships between children and caregivers. Atlanta, GA: Dec 27. 2013 Available at: http://www.cdc.gov/violenceprevention/pdf/cm_strategic_direction-long-a.pdf [Accessed January 21, 2014]

8. Center on the Developing Child at Harvard University. [Accessed January 20, 2014] The Foundations of Lifelong Health are Built in Early Childhood. 2010. Available at: http:// www.developingchild.harvard.edu

9. Belsky J. Etiology of child maltreatment: A development-ecological analysis. Psychological Bulletin. 1993; 114:413-34. [PubMed: 8272464] 
10. Bronfenbrenner U. Contexts of child rearing: Problems and prospects. American Psychologist. 1979; 34:844-850.

11. Sedlak, A.; Mettenburg, J.; Basena, M., et al. Fourth National Incidence Study of Child Abuse and Neglect (NIS-4): Report to Congress. Washington, DC: 2010. Available at: http:// www.acf.hhs.gov/programs/opre/abuse_neglect/natl_incid/ nis4_report_congress_full_pdf_jan2010.pdf [Accessed September 8, 2010]

12. Sullivan PM, Knutson JF. Maltreatment and disabilities: a population-based epidemiological study. Child Abuse Negl. 2000; 24:1257-73. [PubMed: 11075694]

13. Ammerman RT, Hersen M, Van Hasselt VB, et al. Maltreatment in psychiatrically hospitalized children and adolescents with developmental disabilities: prevalence and correlates. J Am Acad Child Adolesc Psychiatry. 1994; 33:567-76. [PubMed: 8005910]

14. Chaffin M, Kelleher K, Hollenberg J. Onset of physical abuse and neglect: Psychiatric, substance abuse, and social risk factors from prospective community data. Child Abuse Negl. 1996; 20:191200. [PubMed: 8734549]

15. Kelleher K, Chaffin M, Hollenberg J, et al. Alcohol and drug disorders among physically abusive and neglectful parents in a community-based sample. Am J Pub Health. 1994; 84:1586-90. [PubMed: 7943475]

16. Kotch JB, Browne DC, Dufort V, et al. Predicting child maltreatment in the first 4 years of life from characteristics assessed in the neonatal period. Child Abuse Negl. 1999; 23:305-19. [PubMed: 10321769]

17. Bays J. Substance abuse and child abuse-impact of addiction on the child. Pediatr Clin North Am. 1990; 37:881-904. [PubMed: 2199920]

18. Stringer SA, LaGreca AM. Correlates of child abuse potential. Journal of Abnormal Child Psychology. 1985; 13:217-226. [PubMed: 4008753]

19. Ellis RH, Milner JS. Child abuse and locus of control. Psychological Reports. 1981; 48:507-510. [PubMed: 7291388]

20. Nurius PS, Lovell M, Maggie E. Self-appraisals of abusive parents: A contextual approach to study and treatment. Journal of Interpersonal Violence. 1988; 3:458-467.

21. Appel A, Holden G. The co-occurrence of spose and physical child abuse: a review and appraisal. J Fam Psych. 1998; 12:578-599.

22. Stiffman MN, Schnitzer PG, Adam P, et al. Household composition and risk of fatal child maltreatment. Pediatrics. 2002; 109:615-21. [PubMed: 11927705]

23. Coulton CJ, Korbin JE, Su M. Neighborhoods and child maltreatment: a multi-level study. Child Abuse Negl. 1999; 23:1019-1040. [PubMed: 10604060]

24. Coulton CJ, Crampton DS, Irwin M, et al. How neighborhoods influence child maltreatment: a review of the literature and alternative pathways. Child Abuse Negl. 2007; 31:1117-1142. [PubMed: 18023868]

25. McCurdy K. The influence of support and stress on maternal attitudes. Child Abuse Negl. 2005; 29:251-68. [PubMed: 15820542]

26. Lyons SJ, Henly JR, Schuerman JR. Informal support in maltreating families: Its effect on parenting practices. Children and Youth Services Review. 2005; 27:21-38.

27. Coleman PK, Karraker KH. Self-efficacy and parenting quality: Findings and future applications. Developmental Review. 1998; 18:47-85.

28. Runyan DK, Hunter WN, Socolar R, et al. Children who prosper in unfavorable environments: The Impact of social capital. Pediatrics. 1998; 101:12-18. [PubMed: 9417144]

29. Ewing JA. Detecting alcoholism: The CAGE Questionnaire. JAMA. 1984; 252:1905-1907. [PubMed: 6471323]

30. Feldhaus KM, Koziol-McLain J, Amsbury HL, et al. Accuracy of 3 brief screening questions for detecting partner violence in the Emergency Department. JAMA. 1997; 277:1357-1361. [PubMed: 9134940]

31. Weiss SJ, Ernst AA, Cham E, et al. Development of a screen for ongoing intimate partner violence. Violence and victims. 2003; 18:131-141. [PubMed: 12816400] 
32. Whooley MA, Avins AL, Miranda J, et al. Case-finding instruments for depression. Two questions are as good as many. Journal of General Internal Medicine. 1997; 12:439-45. [PubMed: 9229283]

33. Hinkin $\mathrm{CH}$, Castellon SA, Dickson-Fuhrman E, et al. Screening for drug and alcohol abuse among older adults using a modified version of the CAGE. Am J Addictions. 2001; 10:319-26.

34. Brown RL, Rounds LA. Conjoint screening questionnaires for alcohol and other drug abuse: criterion validity in a primary care practice. Wisconsin Medical Journal. 1995; 94:135-40. [PubMed: 7778330]

35. Dubowitz H, Feigelman S, Lane W, et al. Screening for depression in an urban pediatric primary care clinic. Pediatrics. 2007; 119:435-43. [PubMed: 17332195]

36. Dubowitz H, Prescott L, Feigelman S, et al. Screening for Intimate Partner Violence in an Urban Pediatric Primary Care Clinic. Pediatrics. 2008; 121:e85-91. [PubMed: 18166548]

37. Lane WG, Dubowitz H, Feigelman S, et al. Screening for substance abuse in pediatric primary care. Amb Peds. 2007; 7:458-462.

38. Staal IIE, vandenBrink HAG, Hermanns JMA, et al. Assessment of parenting and developmental problems in toddlers: development and feasibility of a structured interview. Child: care, health and development. 2011; 37:503-511.

39. Staal IIE, Hermanns JMA, Schrijvers JP, et al. Risk assessment of parents' concerns at 18 months in preventive child health care predicted child abuse and neglect. Child Abuse Negl. 2013; 37:475-484. [PubMed: 23352082]

40. Dubowitz H, Feigelman S, Lane W, et al. Pediatric primary care to help prevent child maltreatment: the Safe Environment for Every Kid (SEEK) Model. Pediatrics. 2009; 123:858-864. [PubMed: 19255014]

41. Dubowitz H, Lane WG, Semiatin JN, et al. The SEEK model of pediatric primary care: can child maltreatment be prevented in a low-risk population? Acad Pediatr. 2012; 12:259-68. [PubMed: 22658954]

42. Lane, WG.; Frick, K.; Dubowitz, H., et al. Cost-Effectiveness analysis of the SEEK(A Safe Environment for Every Kid) child maltreatment prevention program; American Public Health Association 139th Annual Meeting and Exposition; Washington, D.C.. 2011; Nov 1.

43. Dias MS, Smith K, DeGuehery K, et al. Preventing abusive head trauma among infants and young children: A hospital-based parent education program. Pediatrics. 2005; 115:e470. [PubMed: 15805350]

44. Keenan HT, Leventhal JM. A Case-Control study to evaluate Utah's shaken baby prevention program. Academic Pediatrics. 2010; 10:389-394. [PubMed: 21075319]

45. Barr RG, Rivara FP, Barr M, et al. Effectiveness of educational materials designed to change knowledge and behaviors regarding crying and shaken-baby syndrome in mothers of newborns: a randomized controlled trial. Pediatrics. 2009; 123:972-980. [PubMed: 19255028]

46. Barr RG, Barr M, Fujiwara T, et al. Do educational materials change knowledge and behavior about crying and shaken baby syndrome? A randomized controlled trial. CMAJ. 2009; 180:727_ 733. [PubMed: 19255065]

47. Runyan DK, Hennink-Kaminski HJ, Zolotor AJ, et al. Design and testing of a shaken baby syndrome prevention program - The Period Of Purple Crying: Keeping Babies Safe in North Carolina. Social Marketing Quarterly. 2009; 15:2-24.

48. Levin-Goodman, R. Final Report. American Academy of Pediatrics; Elk Grove Village, IL: Jan. 2009 Connected Kids Implementation Case Studies Project. Available at: http://www2.aap.org/ connectedkids/FinalCaseStudiesReport.pdf [Accessed February 15, 2014]

49. [Accessed January 21, 2014] Practicing Safety: A Child Abuse and Neglect Prevention Improvement Project. Available at: http://www.aap.org/en-us/professional-resources/practicesupport/quality-improvement/Quality-Improvement-Innovation-Networks/Pages/PracticingSafety-A-Child-Abuse-and-Neglect-Prevention-Improvement-Project.aspx

50. Damashek A, Doughty D, Ware L, et al. Predictors of client engagement and attrition in homebased child maltreatment prevention services. Child Maltreatment. 2011; 16:9-20. [PubMed: 21148600]

51. Reynolds AJ, Mathieson LC, et al. Do early childhood interventions prevent child maltreatment?: A review of research. Child Maltreatment. 2009; 14:182-206. [PubMed: 19240245] 
52. Avellar SA, Supplee LH. Effectiveness of home visiting for improving child health and reducing child maltreatment. Pediatrics. 2013; 132:S90. [PubMed: 24187128]

53. Avellar, S.; Paulsen, D.; Sama-Miller, E., et al. Home Visiting Evidence of Effectiveness Review: Executive summary. Office of Planning, Research and Evaluation, Administration for Children and Families, U.S. Department of Health and Human Services; Washington, D.C.: 2013. Available at: http://homvee.acf.hhs.gov/HomVEE_Executive_Summary_2013.pdf [Accessed February 11, 2014]

54. Matone M, O'Reilly ALR, Luan X, et al. Emergency department visits and hospitalizations for injuries among infants and children following statewide implementation of a home visitation model. Matern Child Health J. 2012; 16:1754-1761. [PubMed: 22120426]

55. Easterbrooks, MA.; Jacobs, FH.; Bartlett, JD., et al. [Accessed: February 11, 2014] Initial findings from a randomized controlled trial of Healthy Families Massachusetts: early program impacts on young mothers' parenting. Pew states home visitation evaluation. Available at: http://

www.pewstates.org/uploadedFiles/PCS_Assets/2013/Healthy_Families_Massachusetts_report_pdf

56. Mikton C, Butchart A. Child maltreatment prevention: A systematic review of reviews. Bull World Health Organ. 2009; 87:1-9.

57. MacLeod J, Nelson G. Programs for the promotion of family wellness and the prevention of child maltreatment: a meta-analytic review. Child Abuse Negl. 2000; 24:1127-1149. [PubMed: 11057701]

58. Lundahl BW, Nimer J, Parsons B. Preventing child abuse: A meta-analysis of parent training programs. Research on Social Work Practice. 2006; 16:251-262.

59. Barlow J, Coren E, Stewart-Brown SSB. Parent-training programmes for improving maternal psychosocial health. Cochrane Database of Systematic Reviews. 2003; (4) Art. No.: CD002020. DOI: 10.1002/14651858.CD002020.pub2.

60. Geeraert L, Van den Noortgate W, Grietens H, et al. The effects of early prevention programs for families with young children at risk for physical abuse and neglect: A meta-analysis. Child Maltreatment. 2004; 9:277-291. [PubMed: 15245680]

61. Sanders MR, Cann W, Markie-Dadds C. The Triple P-Positive Parenting Programme: A universal population-level approach to the prevention of child abuse. Child Abuse Review. 2003; 12:155171.

62. Prinz RJ, Sanders MR, Shapiro CJ, et al. Population-based prevention of child maltreatment: The U.S. Triple P System population trial. Prev Sci. 2009; 10:1-12. [PubMed: 19160053]

63. Berrick J, Barth R. Child sexual abuse prevention training: what do they learn? Child Abuse Negl. 1992; 12:543-553. [PubMed: 3233519]

64. Davis MK, Gidyez CA. Child sexual abuse prevention programs: a meta-analysis. Journal of Clinical and Child Psychology. 2000; 29:257-265.

65. Rispens J, Aleman A, Goudena PP. Prevention of child sexual abuse victimization: a meta-analysis of school programs. Child Abuse Negl. 1997; 21:975-987. [PubMed: 9330798]

66. Finkelhor D. The prevention of childhood sexual abuse. The Future of Children. 2009; 19:169194. [PubMed: 19719027]

67. Finkelhor D, Asdigian N, Dziuba-Leatherman J. The effectiveness of victimization prevention programs for children: A follow-up. AJPH. 1995; 85:1684-1689.

68. Zwi KJ. School-based education programs for the prevention of child sexual abuse. Cochrane Database for Systematic Review. 1999; 73:281-313.

69. Gibson LE, Leitenberg H. Child sexual abuse prevention programs: Do they decrease the occurrence of child sexual abuse? Child Abuse Negl. 2000; 24:1115-1125. [PubMed: 11057700]

70. Binder R, McNiel D. Evaluation of a school-based sexual abuse prevention program: cognitive and emotional effects. Child Abuse Negl. 1987; 11:497-506. [PubMed: 3427510]

71. Chasen-Taber L, Tabachnick J. Evaluation of a child sexual abuse prevention program Sexual Abuse: Journal of Research and Treatment. 1999; 11:279-292.

72. Rheingold AA, Campbell C, Self-Brown S, et al. Prevention of child sexual abuse: evaluation of a community media campaign. Child Maltreat. 2007; 12:352-363. [PubMed: 17954941] 
73. Harding K, Galano J, Martin J, et al. Healthy Families America Effectiveness: A comprehensive review of outcomes. Journal of Prevention and Intervention in the Community. 2007; 34:149-179. [PubMed: 17890198]

74. Gonzalez A, MacMillan HL. Preventing child maltreatment: An evidenced-based update. J Postgrad Med. 2008; 54:280-286. [PubMed: 18953147]

75. Olds DL, Henderson CR, Chamberlin R, et al. Preventing child abuse and neglect: a randomized trial of nurse home visitation. Pediatrics. 1986; 78:65-78. [PubMed: 2425334]

76. Olds DL, Eckenrode J, Henderson CR, et al. Long-term effecs of home visitation on maternal life course and child abuse and neglect. Fifteen-year follow-up of a randomized trial. JAMA. 1997; 278:637-643. [PubMed: 9272895]

77. Olds DL, Kitzman H, Hanks C, et al. Effects of nurse home visiting on maternal and child functioning: Age-9 follow-up of a randomized trial. Pediatrics. 2007; 120:e832-845. [PubMed: 17908740]

78. Love, JM.; Kisker, EE.; Ross, CM., et al. Volume I: Final technical report. Office of Planning, Research and Evaluation, Administration for Children and Families, U.S. Department of Health and Human Services; Washington, DC: Jun. 2002 Making a difference in the lives of infants and toddlers and their families: the impacts of Early Head Start. Available at: http://www.acf.hhs.gov/ sites/default/files/opre/impacts_vol1.pdf [Accessed February 6, 2014]

79. Drazen, SM.; Haust, M. [Accessed February 6, 2014] Raising reading readiness in low-income children by parent education. Paper presented at the annual meeting of the American Psychological Association. Aug. 1993 Available at: http://homvee.acf.hhs.gov/Effects.aspx? rid $=1 \&$ sid $=16 \&$ mid $=5 \&$ oid $=4$ 


\section{Box 1}

\section{Opportunities for Child Maltreatment Prevention in Pediatric Primary Care}

1. Screen for child maltreatment risk factors, including parental depression, substance abuse, intimate partner violence, parental stress, harsh punishment, and food insecurity

2. Identify family protective factors (e.g. social support, self-efficacy, parenting competence)

3. Provide anticipatory guidance about challenging behaviors and developmental issues that may increase the risk for maltreatment (e.g. infant crying, toilet training)

4. Ask parents about discipline and help them replace corporal punishment with more effective and less harmful strategies

5. Discuss sexual development and behavior with parents. Help parents and children become more skilled in communication about sexuality and sexual abuse (see Table 4)

6. Become knowledgeable about the availability and effectiveness of local community-based resources. Encourage families to use your expertise to identify services that meet their needs.

7. Advocate for implementation and sustaining of community-based services to help families prevent maltreatment.

8. Advocate for implementation and sustaining of federal, state, and local programs that ameliorate underlying maltreatment risk factors (e.g. poverty, substance abuse, depression and other mental health disorders) 
Box 2

Home Visiting Programs Meeting DHHS Criteria for an Evidence-Based Early Childhood Home Visiting Model

\begin{tabular}{|l|l|}
\hline ChildFIRST & Healthy Steps \\
\hline Early Head Start-Home Visiting (EHS) & $\begin{array}{l}\text { Home Instruction for Parents of Preschool } \\
\text { Youngsters (HIPPY) }\end{array}$ \\
\hline $\begin{array}{l}\text { Early Intervention Program for } \\
\text { Adolescent Mothers (EIP) }\end{array}$ & Nurse Family Partnership (NFP) \\
\hline Early Start (New Zealand) & $\begin{array}{l}\text { Oklahoma's Community-Based Family } \\
\text { Resource and Support (CBFRS) Program }\end{array}$ \\
\hline Family Check-Up & Parents as Teachers (PAT) \\
\hline Healthy Families America (HFA) & $\begin{array}{l}\text { Play and Learn Strategies (PALS) for } \\
\text { Infants }\end{array}$ \\
\hline
\end{tabular}




\section{Key Points}

1. Prevention of child maltreatment can be incorporated into pediatric practice through anticipatory guidance, risk factor screening, and referral to communitybased resources

2. There is wide variation in the methods and effectiveness of community-based prevention programs. Pediatricians should therefore be knowledgeable about what programs are available in their community and the evidence-based support for those programs

3. Pediatricians can be effective prevention advocates at the level of the individual patient and family, as well as at the local, regional, and national level. 
Table 1

Examples of Child Maltreatment Risk Factors by Ecological Level

\begin{tabular}{|c|c|c|c|}
\hline Child & Parent & Family & Community/Society \\
\hline Prematurity & Teenage parent & $\begin{array}{l}\text { Intimate partner } \\
\text { violence }\end{array}$ & $\begin{array}{l}\text { Violent/unsafe } \\
\text { neighborhood }\end{array}$ \\
\hline Colic/fussy baby & $\begin{array}{l}\text { Depression/Anxiety/ } \\
\text { other mental health } \\
\text { conditions }\end{array}$ & Single parent & $\begin{array}{l}\text { Lack of availability of } \\
\text { affordable, high } \\
\text { quality child care }\end{array}$ \\
\hline Chronic illness & Substance abuse & Poverty & $\begin{array}{l}\text { Absence of } \\
\text { community activities, } \\
\text { programs for } \\
\text { children }\end{array}$ \\
\hline $\begin{array}{l}\text { Emotional/behavioral } \\
\text { difficulties }\end{array}$ & $\begin{array}{l}\text { Poor impulse } \\
\text { control }\end{array}$ & Unemployment & $\begin{array}{l}\text { Lack of government } \\
\text { support for social } \\
\text { welfare programs }\end{array}$ \\
\hline $\begin{array}{l}\text { Developmental } \\
\text { disability }\end{array}$ & $\begin{array}{l}\text { History of abuse or } \\
\text { harsh punishment } \\
\text { as a child }\end{array}$ & $\begin{array}{l}\text { Non-biologically } \\
\text { related adult living } \\
\text { in the home }\end{array}$ & \\
\hline Physical disability & $\begin{array}{l}\text { Lack of social } \\
\text { support }\end{array}$ & & \\
\hline Unwanted child & Single parent & & \\
\hline \multirow[t]{2}{*}{ Multiple gestation } & $\begin{array}{l}\text { Poor knowledge of } \\
\text { normal child } \\
\text { development \& } \\
\text { behavior }\end{array}$ & & \\
\hline & Major stress & & \\
\hline
\end{tabular}




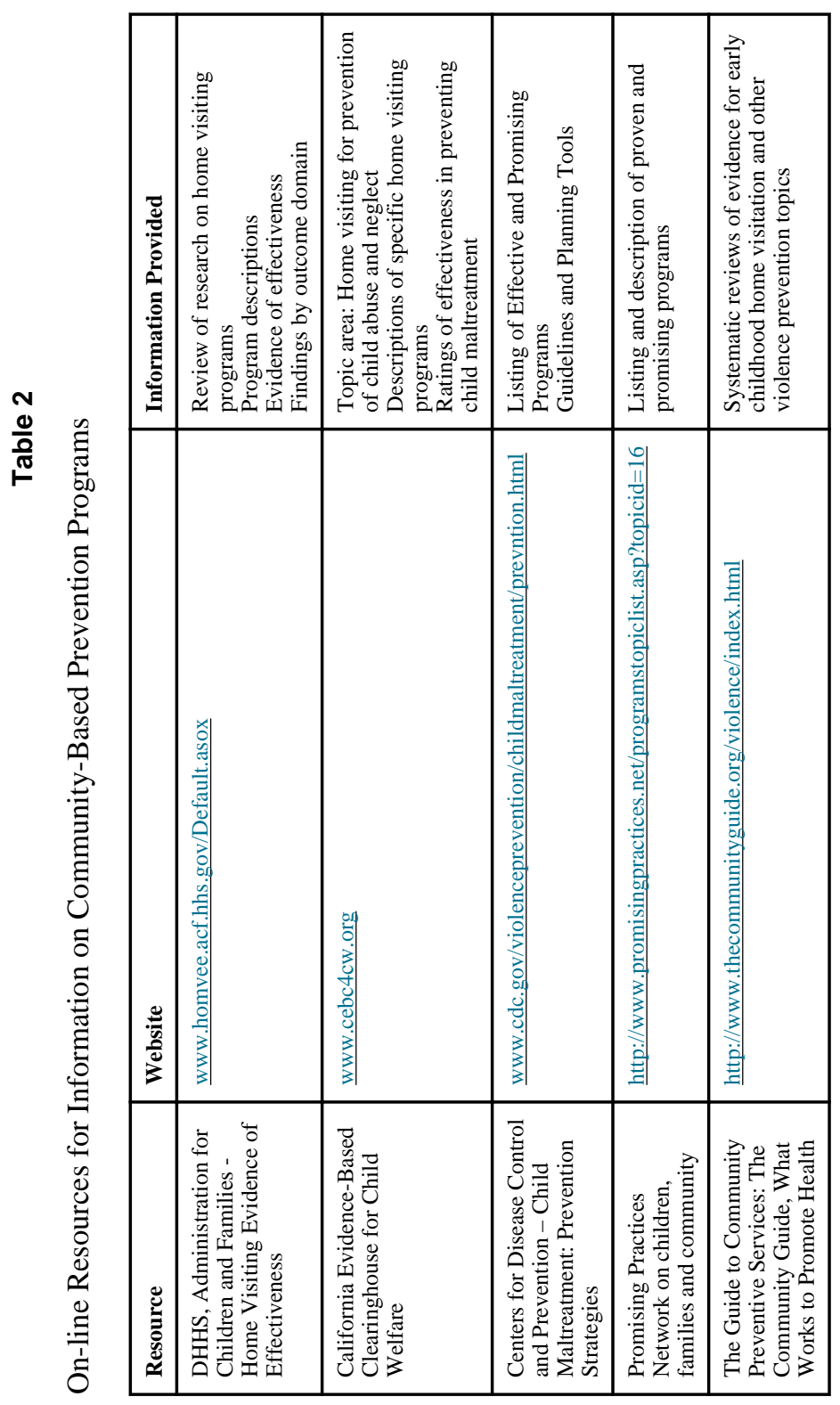

Pediatr Clin North Am. Author manuscript; available in PMC 2015 October 01. 


\begin{tabular}{|c|c|c|c|c|}
\hline 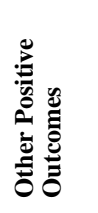 & 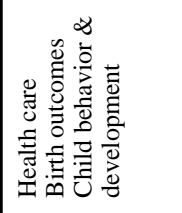 & 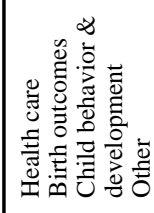 & 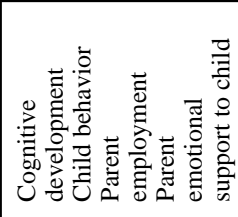 & 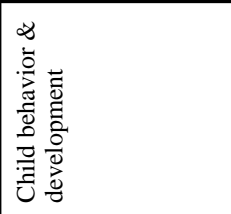 \\
\hline 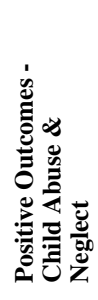 & 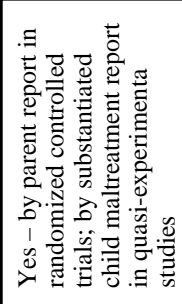 & 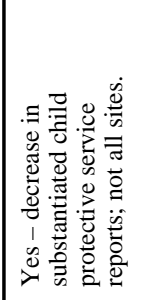 & 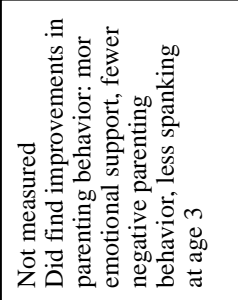 & 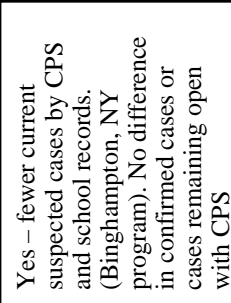 \\
\hline 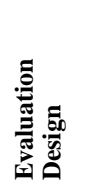 & 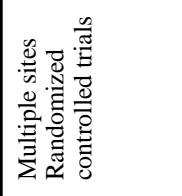 & 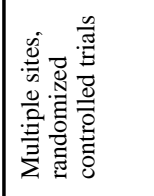 & 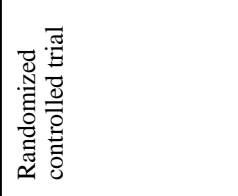 & 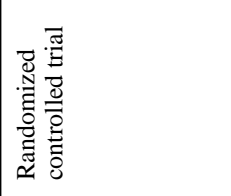 \\
\hline 战 & 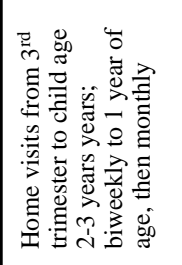 & 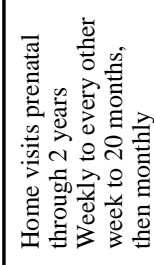 & 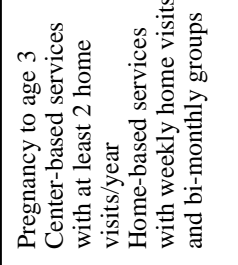 & 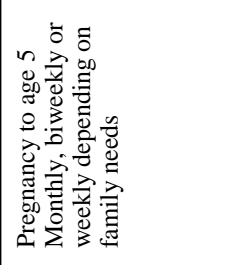 \\
\hline & 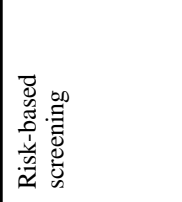 & 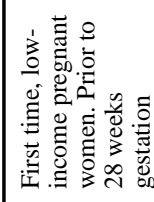 & 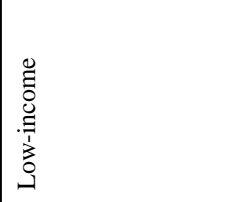 & 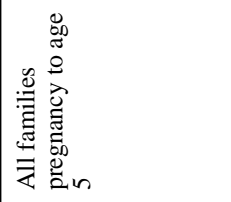 \\
\hline 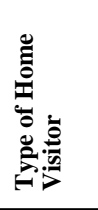 & 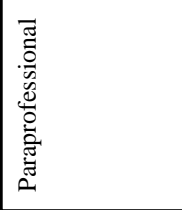 & 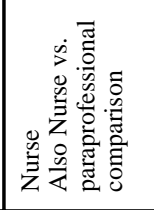 & 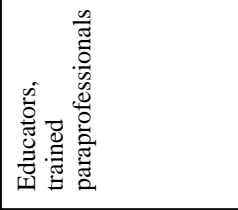 & 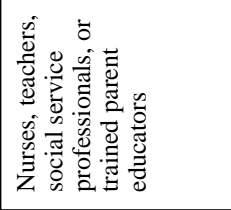 \\
\hline 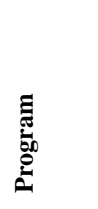 & 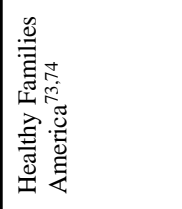 & 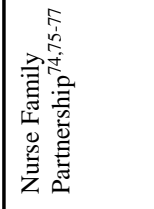 & 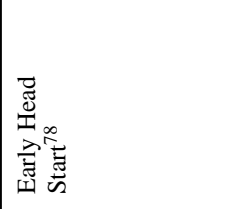 & 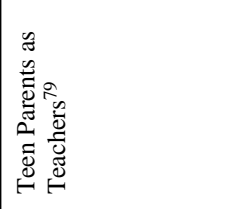 \\
\hline
\end{tabular}

Pediatr Clin North Am. Author manuscript; available in PMC 2015 October 01. 


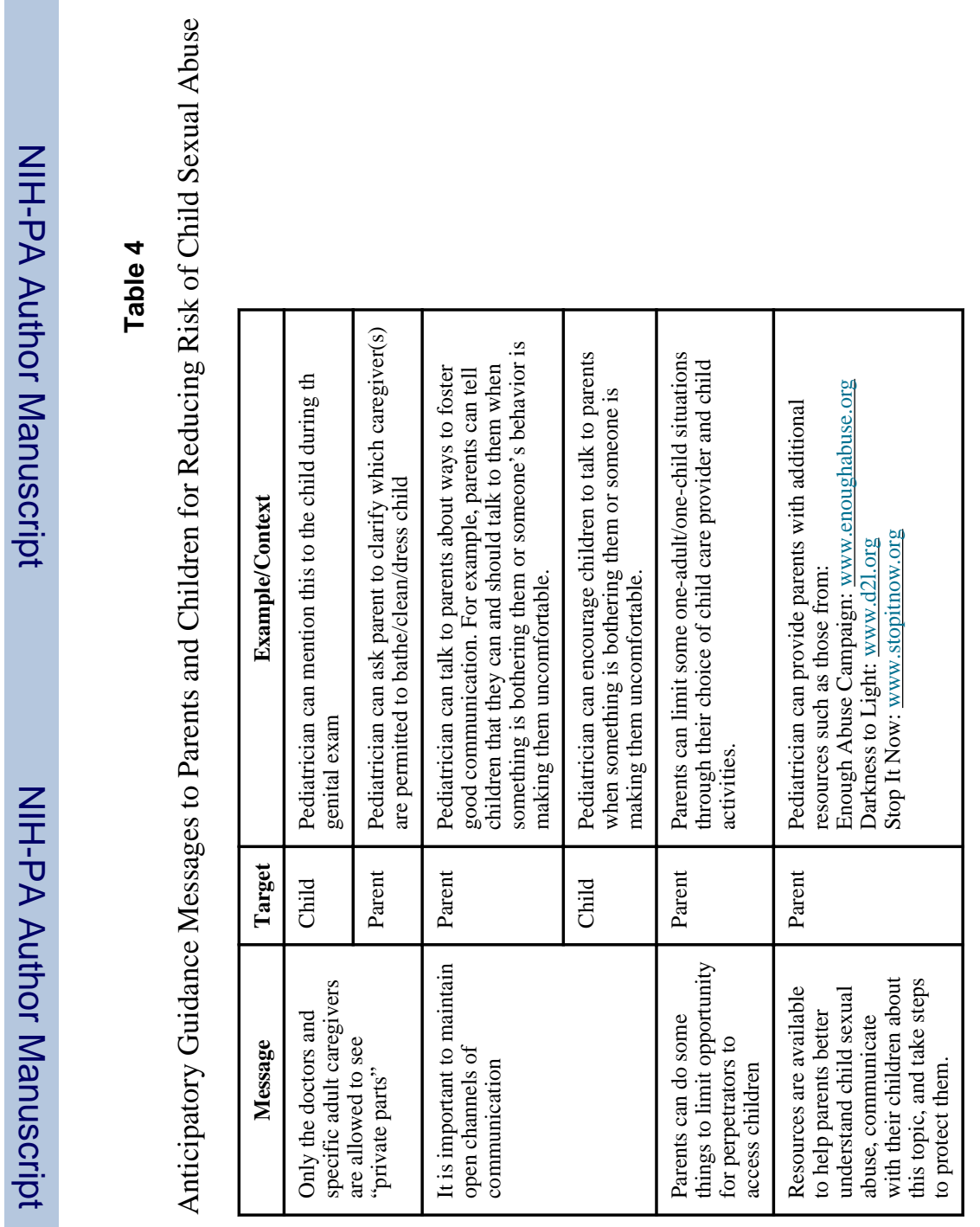

Pediatr Clin North Am. Author manuscript; available in PMC 2015 October 01. 